\title{
Synthesis, characterization and ampyrone drug release behavior of magnetite nanoparticle/2,3-dialdehyde cellulose- 6-phosphate composite
}

\author{
Sherif M. A. S. Keshk (1) Adel A. El-Zahhar • Qana A. Alsulami • \\ Mariusz Jaremko $\cdot$ Samir Bondock - Thomas Heinze
}

Received: 21 July 2019/Accepted: 25 November 2019

(C) Springer Nature B.V. 2019

\begin{abstract}
In this study, a magnetically enhanced drug delivery composite was synthesized by coprecipitating magnetite nanoparticle (MNP) with 2,3-dialdehyde cellulose-6-phosphate (DACP) and investigated for ampyrone drug loading and controlled delivery. The magnetic core containing $\mathrm{Fe}_{3} \mathrm{O}_{4}$ was synthesized through the intramolecular Cannizzaro reaction during the in situ preparation of MNPs in the presence of sodium hydroxide solution, producing hydroxyl acid cellulose phosphate (HACP). The prepared magnetite nanocomposite MNP/HACP was characterized using FT-IR, SEM-EDX, XRD, TEM, VSM and TGA. The release profiles of ampyrone loaded on MNP/HACP showed a continuous release
\end{abstract}

\section{S. M. A. S. Keshk ( $\bowtie)$}

Nanomaterials and Systems for Renewable Energy Laboratory, Research and Technology Center of Energy, Technoparc borje cedria, BP 095, Hammam Lif, Tunisia e-mail: keshksherif@gmail.com

A. A. El-Zahhar · S. Bondock Department of Chemistry, College of Science, King Khalid University, P.O. Box 9004, Abha 61413, Saudi Arabia

\author{
A. A. El-Zahhar \\ Hot Labs., Nuclear Chemistry Department, Center Atomic \\ Energy Authority, Cairo 13759, Egypt
}

\section{Q. A. Alsulami}

Chemistry Department, Faculty of Science, King Abdulaziz University, P.O. Box 42805, Jeddah 21589 , Saudi Arabia rate of more than $95 \%$ after $50 \mathrm{~h}$, compared to the lower release rate of DACP, where only $60 \%$ of the loaded ampyrone was released after $50 \mathrm{~h}$. These results show that MNP/HACP nanocomposites present an enhanced loading-release system with the potential to act as a magnetically enhanced drug delivery system.

Keywords 2,3-Dialdehyde cellulose-6-phosphate · Magnetite $\cdot$ Ampyrone $\cdot$ Drug carrier

\author{
M. Jaremko \\ Biological and Environmental Science and Engineering \\ (BESE), King Abdullah University of Science and \\ Technology (KAUST), Thuwal 23955-6900, Saudi Arabia \\ S. Bondock \\ Chemistry Department, Faculty of Science, Mansoura \\ University, Mansoura, Egypt \\ T. Heinze \\ Center of Excellence for Polysaccharide Research, \\ Institute of Organic Chemistry and Macromolecular \\ Chemistry, Friedrich Schiller University Jena, \\ Humboldtstr. 10, 07743 Jena, Germany
}




\section{Introduction}

The pharmaceutical industry has a significant interest in developing and improving drug delivery in the human body. Certain polymers can be designed and modified to improve drug loading-release properties and drug delivery. For example, the chemical and physical features of the polymer cellulose can be modified by physico-chemical methods to take advantage of certain attributes of cellulose that are desirable for drug development. These physico-chemical methods aim to break hydrogen bonds or replace a hydroxyl group or a hydrogen bond with a functional group in cellulose chains in order to take advantage of some of the favorable properties of cellulose (Keshk et al. 2019a, b). Cellulose and its derivatives are employed in several medical applications, either as unmodified biopolymers, esters and ethers of cellulose, or as crosslinked or grafted copolymers (Keshk and Gouda 2017). In the pharmaceutical industry, different forms of pure cellulose (powdered cellulose, low crystallinity cellulose, and microcrystalline cellulose) or cellulose derivatives are used as an excipient to control and/or sustain drug release, to coat tablets (osmotic and enteric coating), to increase the muco-adhesiveness of the formulation and to enhance the compressibility of the powder mixture (Liechty et al. 2010; Shokri and Adibki 2013). There are many excipients derived from cellulose used in drug preparations that improve manufacturing processes, decrease costs and improve the performance of medicine. Different modification methods have been investigated and developed to create more favorable cellulose-based excipients (Dias and Duarte 2013). Specific polymers can be used to control the release of active pharmaceutical ingredients (API) in constant doses over long periods, increase the stability of the API by entrapping it within the matrix of a polymer, tuning the release of both hydrophilic and hydrophobic drugs through swelling, and eroding the nature of the polymers (Godwin et al. 2001; Kim et al. 2008). Cellulose acetate, cellulose acetate phthalate, cellulose acetate butyrate, cellulose acetate tri-melitate and hydroxypropyl methyl cellulose phthalate are commonly used cellulose esters in the pharmaceutical industry (Heinze et al. 2003; Edgar 2004, 2007; Volkert et al. 2009). Cellulose phosphate (CP) has potential for use as an crucial implantable biomaterial in orthopedic applications (Fricain et al. 2001; Keshk et al. 2019a, b). Phosphate functionalities can be used to bind different biologically active species to achieve active surfaces (Leone et al. 2008). Magnetic $\mathrm{Fe}_{3} \mathrm{O}_{4}$ based particles are a crucial element of magnetic solidphase extraction because of their high magnetic saturation values, large surface areas, sufficient adsorption capacities, ease of operation and flexibility for modification (Zhang et al. 2016). However, magnetic $\mathrm{Fe}_{3} \mathrm{O}_{4}$-based particles have some disadvantages that limit their use in practice, such as their susceptibility to aggregate or oxidize, their instability under acidic conditions, and their low extraction efficiency. Their instability under acidic conditions makes them advantageous for drug delivery. Recently, magnetic particles have been employed to carry drugs to the desired target location in the body, typically cancer tissues. Coating the magnetic nanoparticle with organic or inorganic materials significantly improves their biocompatibility and consequently their medical applications (Aguilera et al. 2019). Carboxymethyl cellulose-magnetite nanocomposite was prepared, characterized and applied as drug delivery system. The polysaccharide coated biocompatible magnetite composite showed improved properties in drug loading and aqueous stability (Aguilera et al. 2019). Polyarabic coated magnetic composite was prepared and applied as drug delivery and imaging system for cancer therapeutic applications (Patitsa et al. 2017) and showed improved properties compared to the commercially used materials. Nanostructured composite materials supplemented with trace metals were prepared and studied as intracellular zinc uptake system (Urquiza et al. 2017) and showed greatly enhanced behavior.

The strategy of utilizing magnetic nanoparticle has gathered much consideration from the pharmaceutical industry because of their potential to improve drug delivery in the body, while reducing side effects, and the amount of drug consumption. Thus, biocompatible magnetic nanoparticle can be compressed with drugs, working as drug delivery carriers and controlling the release of the drug in the body. Several improved magnetic nanoparticles have been studied in this context. Magnetic $\mathrm{Fe}_{3} \mathrm{O}_{4} / \mathrm{SiO}_{2}-\mathrm{GO}$ core/shell nanoparticle have been prepared and used as adsorbent. Results have shown that magnetic $\mathrm{Fe}_{3} \mathrm{O}_{4} / \mathrm{SiO}_{2}-\mathrm{GO}$ core/shell nanoparticle has a relatively high adsorption capacity (Yao et al. 2012). Magnetic iron oxide $\left(\mathrm{Fe}_{3} \mathrm{O}_{4}\right)$ nanoparticle has been modified by chitosan 
(CS) using the reverse micro-emulsion (water-in-oil) method. This composite has a relatively small size, but with good magnetic properties and high adsorption capacity (Pham et al. 2010). Recently, Keshk et al. (2019a, b, c) described how 2,3-dialdehyde cellulose (DAC) and 2,3-dialdehyde cellulose-6-phosphate (DACP) experienced an intramolecular Cannizzaro reaction during an in situ reaction with MNP, producing hydroxy acid. 4-ampyrone (4-AA) is a metabolite of aminopyrine with analgesic, anti-inflammatory and antipyretic properties. It is used as a reagent for biochemical reactions, producing peroxides or phenols (Alam et al. 2012). 4-AA is not genotoxic and mutagenic in vivo, but it can interfere with the biological activities of DNA damaging agents and may reduce the effectiveness of DNA damage-based chemotherapy (Radi et al. 2012). In this study, the reaction of $\mathrm{Fe}_{3} \mathrm{O}_{4}$ magnetite nanoparticle with DACP to form MNPs/hydroxy acid cellulose phosphate (HACP) composite is described. The efficiency of this composite to trap and release 4-AA was then studied for the first time using a UV spectrophotometer.

\section{Materials and methods}

Chemicals

All chemicals and cellulose-6-phosphate were purchased from Sigma-Aldrich and used as received. The phosphorus content of cellulose 6-phosphate was 12.25\% (Keshk et al. 2019a).

Preparation of 2,3-dialdehyde cellulose-6phosphate (DACP)

Cellulose-6-phosphate (CP, 0.726 g, $0.003 \mathrm{~mol}$ ) was suspended in $50 \mathrm{ml}$ water for $2 \mathrm{~h}$. Potassium periodate $(1.4 \mathrm{~g}, 0.006 \mathrm{~mol})$ was added slowly and the blend was warmed to $60{ }^{\circ} \mathrm{C}$ for $2 \mathrm{~h}$. Once cooled, the blend was stored in the dark at room temperature for $48 \mathrm{~h}$. The product (DACP) was washed with distilled water. The yield of DACP was $96 \%$.

\section{Preparation of MNP/HACP nanocomposites}

The in situ precipitation method described in Keshk et al. (2019b) was used to prepare the DACP magnetic nanoparticle composite (MNP/HACP). Briefly, $3.0 \mathrm{~g}$
DACP was suspended in $100 \mathrm{~mL}$ deionized water and blended with $100 \mathrm{~mL}$ aqueous solution of ferrous sulfate heptahydrate $\left(\mathrm{FeSO}_{4} \cdot 7 \mathrm{H}_{2} \mathrm{O}\right)$ and ferric chloride hexahydrate $\left(\mathrm{FeCl}_{3} \cdot 6 \mathrm{H}_{2} \mathrm{O}\right)$ with a stoichiometric proportion of 1:2.

\section{Characterization of MNP/HACP nanocomposites}

A Bruker FT-IR IFS 66 spectrophotometer was used for FT-IR analysis. The morphology of the composite samples was analyzed using field emission scanning electron microscopy FESEM JEOL 6340 type with an energy-dispersive X-ray instrument (EDX) for elemental composition assaying of the composite (El-kott et al. 2019). The surface morphology and particle distribution of the samples were assigned using Titan CT (Thermo Fisher Scientific) operating at $300 \mathrm{kV}$ equipped with a $4 \mathrm{k} \times 4 \mathrm{k} \mathrm{CCD}$ camera (Gatan, Pleasanton, CA, USA). The magnetic properties of the prepared material were analyzed using SQUID-Vibrating sample magnetometer (SVSM, Quantum design, USA). The thermal stability of the sample was assayed using Shimadzu TGA-50H thermal analyzer within temperature range of $25-800{ }^{\circ} \mathrm{C}$ at heating rate of $10{ }^{\circ} \mathrm{C} \mathrm{min}^{-1}$ under controlled nitrogen flow.

In vitro 4-ampyrone drug loading-release experiments

Drug loading of 4-ampyrone (4-AA) on DACP and MNP/HACP nanocomposites was performed by mixing $0.3 \mathrm{~g}$ of either DACP or MNP/HACP with $0.1 \%$ 4-AA dissolved in a water-ethanol mixture (30:70) and stirred for $3 \mathrm{~h}$ to ensure a considerable uptake of 4-AA. After periods of fixed duration, the DACP or MNP/HACP was filtered off at the end. The residual 4-AA concentration in the supernatant was analyzed by UV-vis spectrophotometry and the loading percentage was determined at different time intervals. The release profile of the drug was studied in phosphate-buffered saline (PBS) at $\mathrm{pH}$ 7.4. Either 4-AA-DACP or 4-AA-MNP/HACP (0.3 g) was dispersed in PBS at $37{ }^{\circ} \mathrm{C}$ with slight shaking at $150 \mathrm{rpm}$. After different time intervals, aliquots of $0.5 \mathrm{ml}$ of PBS solution were withdrawn and analyzed for 4-AA concentration using UV-vis spectroscopy. The absorption spectra were assayed within the wavelength range of $200-350 \mathrm{~nm}$, and the concentration 
was calculated depending on the absorption peak at 240-245 nm.

Computational investigations

Various methods for identifying DFT functional groups have been explored. Irfan et al. (2017) have shown that B3LYP provides an exact and reliable description of small molecules. Moreover, the B3LYP functional was shown to be able to reproduce experimental data and to predict several properties of interest. In this study, the ground state geometries and frequency calculations were performed using the B3LYP hybrid functional along with the 6-31G** basis set for $\mathrm{H}, \mathrm{C}, \mathrm{N}, \mathrm{O}$ and $\mathrm{K}$, except for the I atom where LANL2DZ was used. All the calculations were carried out using the Gaussian09 software package (Frisch et al. 2009).

\section{Results and discussion}

Characterization of the prepared magnetic composite

\section{FTIR spectroscopic analysis}

Figure 1 shows the FTIR spectra of CP, DACP and $\mathrm{MNP} / \mathrm{HACP}$ both with and without ampyrone. In the FTIR spectrum of DACP, the band at $1640 \mathrm{~cm}^{-1}$ is attributed to the carbonyl group associated with hydrogen bonding (Keshk et al. 2019a). The broadness and intensity of the DACP bands are probably due to its smaller crystalline size or the orientation effect. The absorption bands at $3388 \mathrm{~cm}^{-1}$ and $1645 \mathrm{~cm}^{-1}$ in the MNP/HACP spectrum are attributed to the hydroxyl and carbonyl groups and stretching of carboxyl group in HACP, respectively (Keshk et al. 2019b).

These results verify the intramolecular Cannizzaro reaction (disproportionation reaction) of DACP, the yielding alcohol and the carboxylic acid (Scheme 1) (Keshk et al. 2019b, c). The presence of $\mathrm{Fe}_{3} \mathrm{O}_{4}$ core is established by the presence of a strong bending vibration band at $752 \mathrm{~cm}^{-1}$ resulting from $\mathrm{Fe}-\mathrm{O}$ stretching (Chan et al., 2005). Furthermore, the redshifts occurring in the carbonyl group in nanocomposites may be due to the interactions between the carboxyl group and $\mathrm{Fe}_{3} \mathrm{O}_{4}$ (Keshk et al. 2019b). The
Fig. 1 FT-IR spectra of cellulose phosphate (CP), dialdehyde cellulose phosphate (DACP) and its magnetic nanocomposite (MNP/HACP), DACP-4-ampyrone and MNP/HACP-4ampyrone

spectrum of DACP/4-AA shows new peaks at $1653 \mathrm{~cm}^{-1}$ and $1563 \mathrm{~cm}^{-1}$ corresponding to the carbonyl group of 4-AA and azomethine group $(\mathrm{C}=\mathrm{N})$, respectively, which are not present in the spectra of MNP/HACP-4-AA. The absorption band of the azomethine group could not be identified in the spectrum of MNP/HACP-4-AA. The stretching vibrational bands of $\mathrm{CH}_{3}$ of 4-AA and $\mathrm{CH}_{2}$ of glucan are recorded at $2929 \mathrm{~cm}^{-1}$ and $2885 \mathrm{~cm}^{-1}$, respectively. These results show the formation of Schiff's bases through the interaction between 4-AA and DACP. Furthermore, 4-AA was attracted by MNP via the formation of Zwitter ions, as verified by the appearance of a broad absorption band at $3388 \mathrm{~cm}^{-1}$ (Scheme 2). The shoulder band at $1485 \mathrm{~cm}^{-1}$ is attributed to the $\mathrm{C}=\mathrm{C}$ stretching vibration of the aromatic ring of 4-AA (Fig. 1), while the peak at $1059 \mathrm{~cm}^{-1}$ is due to the $\mathrm{C}-\mathrm{O}-\mathrm{C}$ vibrational stretch of glucan.

From the previous study, it was confirmed that the favorite places for $\mathrm{OH}$ and $\mathrm{COOH}$ are $\mathrm{C}-2$ and C-3, respectively. On the other hand, DACP reacted with 4ampyrone via two carbonyl groups on C-2 and C-3 (Keshk et al. 2019a, b, c). Computational calculations show that the carbonyl group on C-3 in DACP forms a Schiff's base through the more stable transition state (Fig. 2a) rather than the carbonyl group on C-2 (Fig. 2b). Furthermore, the dipole derivative charges, also known as the atomic polar tensor (APT)-derived charges, were studied, which can be expressed by Eq. (1) as follows:

$q i=\frac{1}{3}\left(\frac{\partial \mu x}{\partial x i}+\frac{\partial \mu y}{\partial y i}+\frac{\partial \mu z}{\partial z i}\right)$

where $\mu$ is the dipole moment of a DACP, and $x_{i}, y_{i}, z_{i}$ are the positions of atom $i$. Although the components of the dipole moment change with the choice of coordinate system, the defined APT charge for each atom is invariant under rotation and translation of the molecule and sum up the total charge of molecule correctly. The determined dipole moment for the Schiff's base that forms between ampyrone and DACP on $\mathrm{C} 3$ is 4.14 , whereas on $\mathrm{C} 2$ the dipole moment is 8.72 in the transition state (Table 1). 

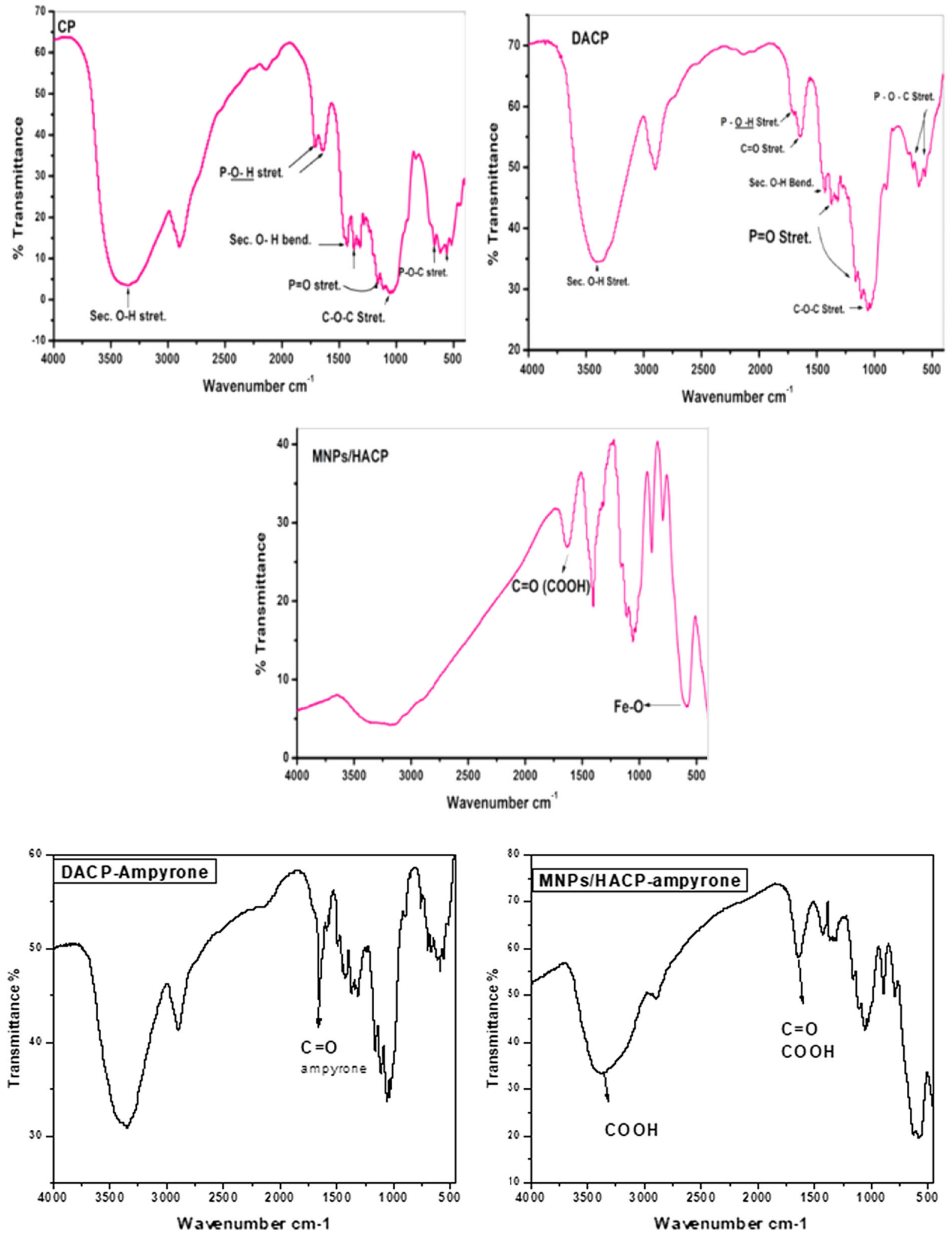


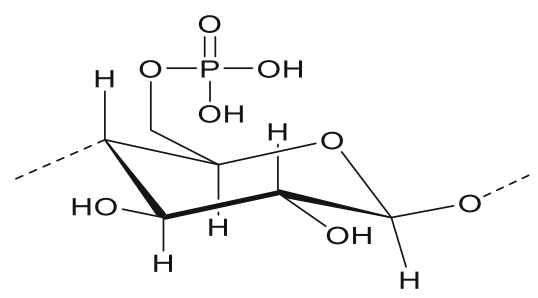

CP

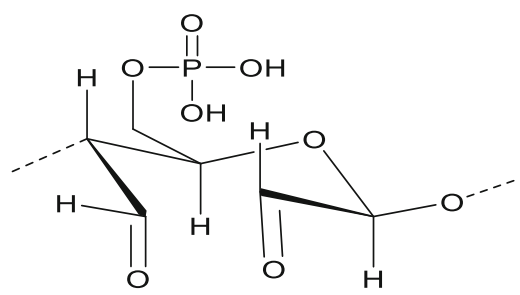

DACP

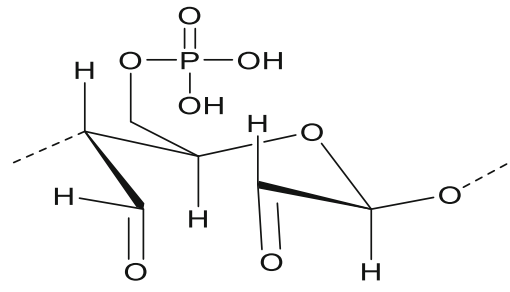

DACP

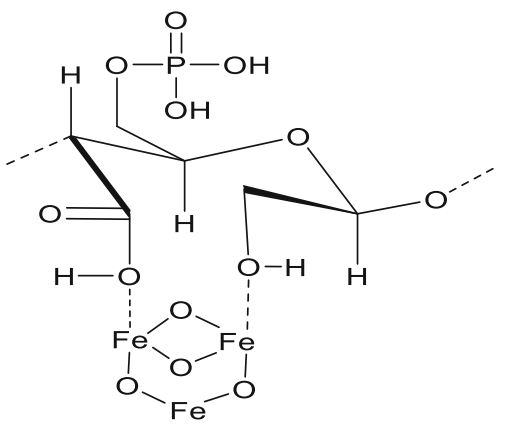

MNPS/HACP

Scheme 1 Synthesis of DACP and MNP/HACP

According to the charge analysis, both the carbonyl groups in DACP could show non-equal opportunities for nucleophilic addition. In the first step, the C-3 atom of the carbonyl group was substituted, and geometrical optimization and frequency calculations were performed. In the second step, the carbonyl group was substituted at C-2 and geometrical optimization and frequency calculations were performed (Fig. 2). It was observed that C-3 stabilizes the Schiff's base by almost $12.02 \mathrm{~kJ} / \mathrm{mol}$. Thus, C-3 carbonyl in DACP is more reactive than $\mathrm{C}-2$ toward the formation of Schiff's base with 4-AA.

\section{SEM-EDX analysis}

The CP sample showed a smoother morphological structure with a stringy appearance. DACP showed an ordinary center root structure, which changed to an extended oval structure with more agglomerations. The interactions between $\mathrm{Fe}_{3} \mathrm{O}_{4}$ and DACP occurred due to physical bonding (Fig. 3). The average diameter of DACP expanded from $58 \mathrm{~nm}$ to $90 \mathrm{~nm}$, affirming the powerful crosslinking of $\mathrm{Fe}_{3} \mathrm{O}_{4}$ nanoparticle with DACP.

The elemental analysis conducted by EDX confirmed the presence of phosphorous and magnetic nanoparticle (Fig. 4). The EDX spectrum reflects the low content of phosphorus compared to other elements as the expected substitution is low, while the sharp peak with high intensity appeared for Fe; reflecting the formation of MNP with higher content ratio. The relative elemental content ratio in the composite sample deduced from the EDX spectrum was found to be $39.09 \%, 38.6 \%, 16.9 \%$, and $5.4 \%$ for $\mathrm{Fe}, \mathrm{O}, \mathrm{C}$ and $\mathrm{P}$, respectively.

\section{X-ray diffraction}

The X-ray diffraction pattern (Fig. 5) displayed two peaks at $2 \theta=15.97^{\circ}$ and $22.74^{\circ}$ for $\mathrm{CP}$, corresponding to the consolidated (1-10) and (110) reflections and the (200) reflection, respectively (Keshk and Salah 2014; Keshk et al. 2019a). The XRD pattern of MNP/ HACP is different from that of DACP (Fig. 5), which shows that the significant change process results in the phase of DACP. The characteristic peaks of $\mathrm{Fe}_{3} \mathrm{O}_{4}$ at $2 \theta=30.1^{\circ}, 35.5^{\circ}, 43.1^{\circ}, 53.4^{\circ}, 57.0^{\circ}$, and $62.6^{\circ}$ can be assigned to the (220), (311), (400), (422), (511), and (440) crystal planes, respectively, proving that the $\mathrm{Fe}_{3} \mathrm{O}_{4}$ nanoparticle had a cubic phase in the composite (JCPDS No. 19-629). 




DACP-Ampyrone Schiff base

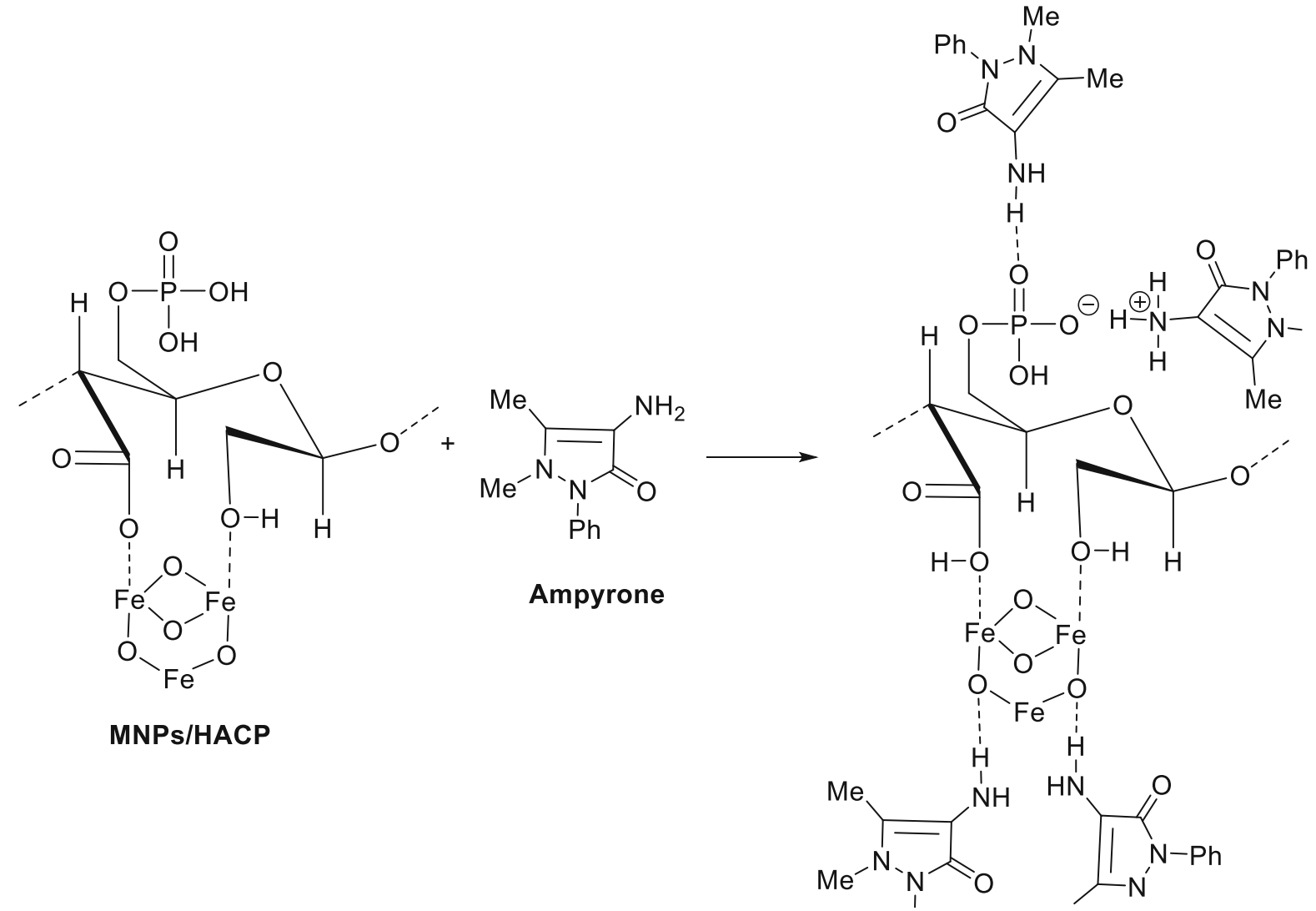

Scheme 2 Loading mechanism of 4-ampyrone on DACP and MNP/HACP 
(a)

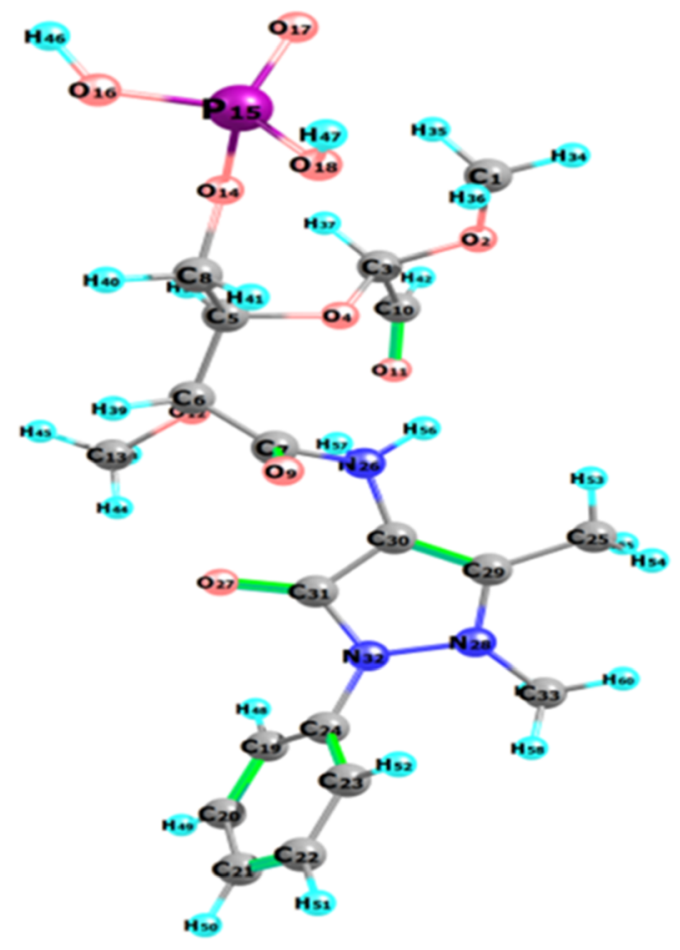

(b)

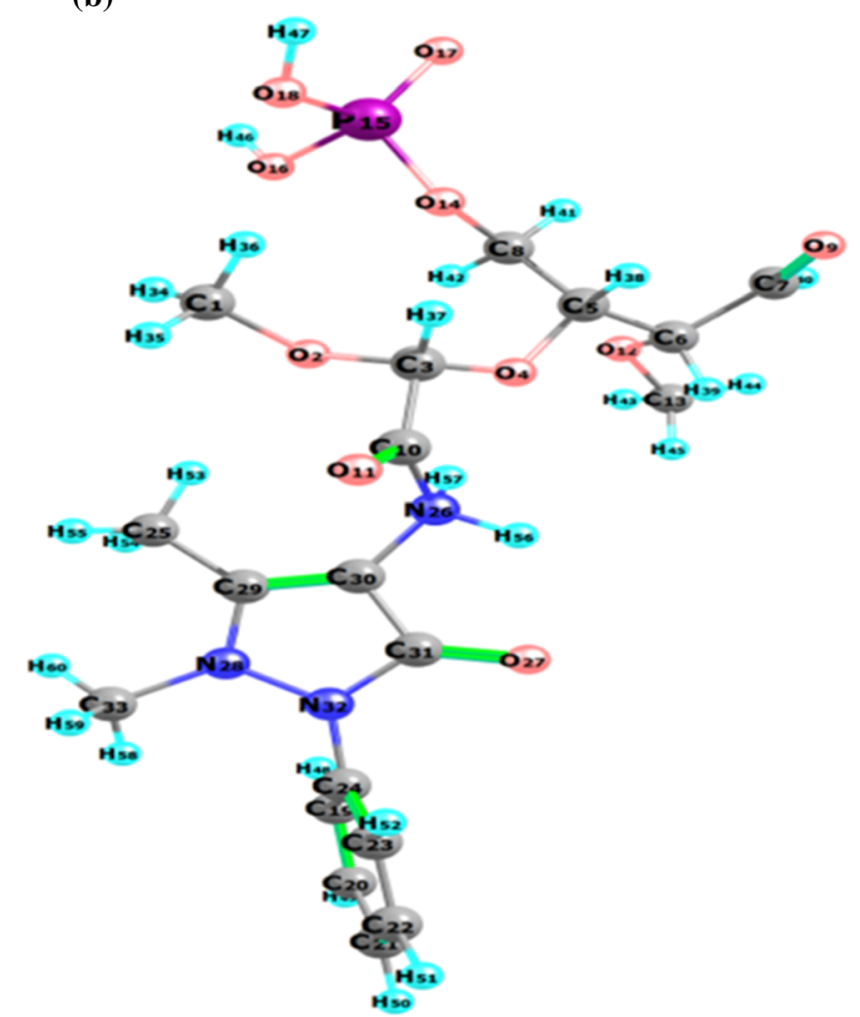

Fig. 2 Optimized geometry for a DACP-C3=O, b DACP-C2=O in transition state

Table 1 Total energies of the DACP-C3=O and DACP-C2 $=\mathrm{O}$ at B3LYP/6-31G*level of theory

\begin{tabular}{lll}
\hline Parameter & DACP-C3=O & DACP-C2=O \\
\hline$\Delta \mathrm{G}(\mathrm{kJ} / \mathrm{mol})$. & 0.0 & 12.02 \\
$\Delta \mathrm{H}(\mathrm{kJ} / \mathrm{mol})$. & 0.0 & 9.67 \\
Dipole moment & 4.14 & 8.72 \\
\hline
\end{tabular}

TEM analysis

The TEM images in Fig. 6 show distinct welldispersed magnetite nanoparticle MNPs within the DACP and have a uniform size and shape. The images of MNP/HACP and MNP/HACP-AA finite MNP distribution of MNP within the polymer and there has appeared very slight agglomeration as a result of higher content ration of MNP. The content of magnetite particles and their homogeneous distribution could reflect higher magnetization properties and induces mutual magnetization (Qu et al. 2013) and/or the dehydration process. The TEM images indicate that the in situ prepared MNP/HACP composite nanocomposite particles have mainly spherical shape with small sizes. Small particle size with reduced agglomeration may result from in situ preparation, as we suggest. It was reported that magnetic nanoparticles with small particle sizes and reduced agglomeration might have the necessary magnetic properties for biomedical applications (Aguilera et al. 2019). The results reflect that the prepared composite particles could provide high magnetization properties.

Magnetic properties

The magnetic nanoparticle is known as composite filling materials and their magnetic properties are greatly affected by their dispersion/aggregation, interparticle interactions, and surface morphology changes (Koksharov 2009; Allia et al. 2014). The magnetic properties of composites containing magnetic materials could be an important indication for the MNP inclusion mechanism as; monodisperse or polydisperse 

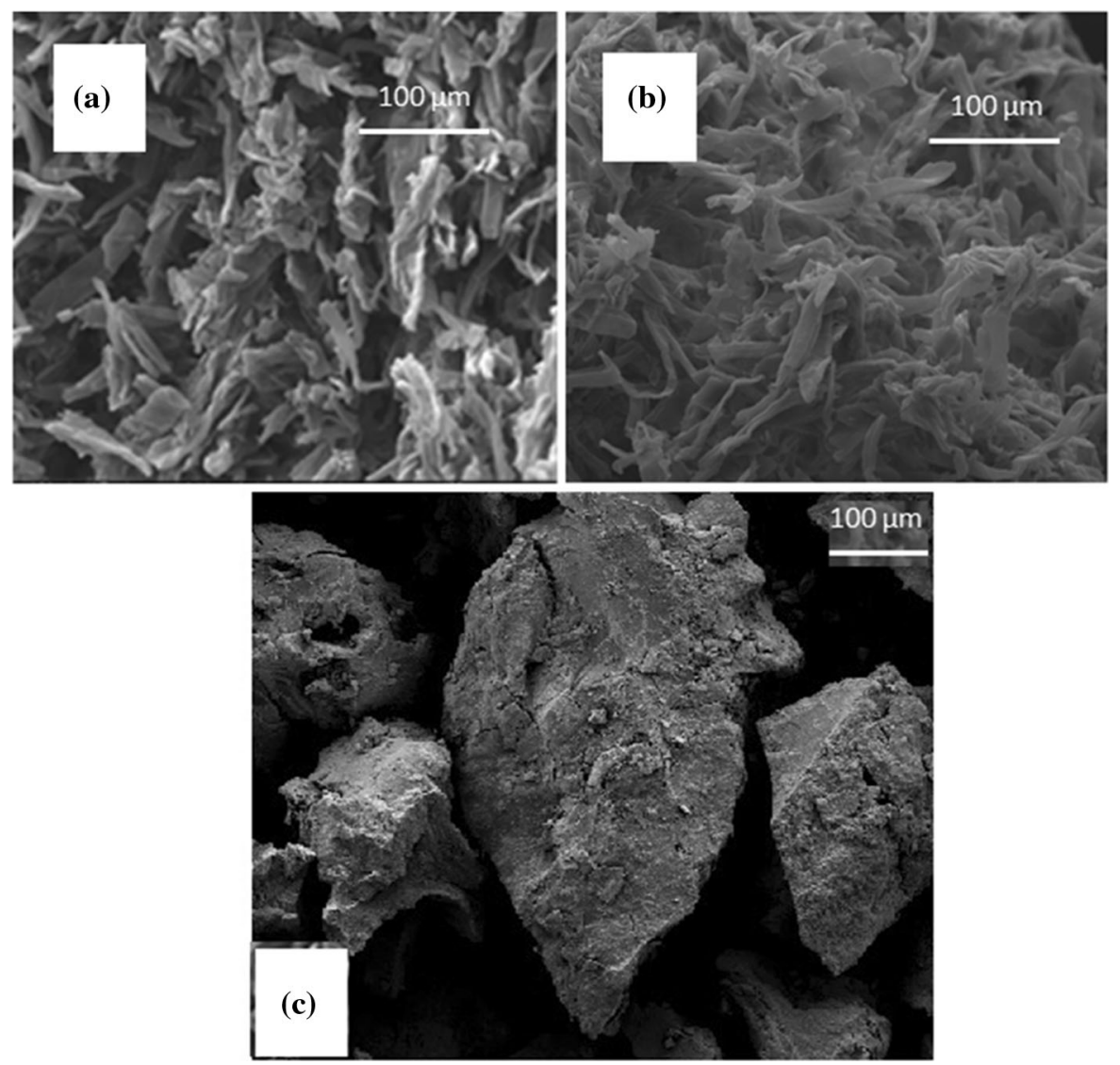

Fig. 3 SEM micrographs of CP (a), DACP (b), and MNP/HACP (c)

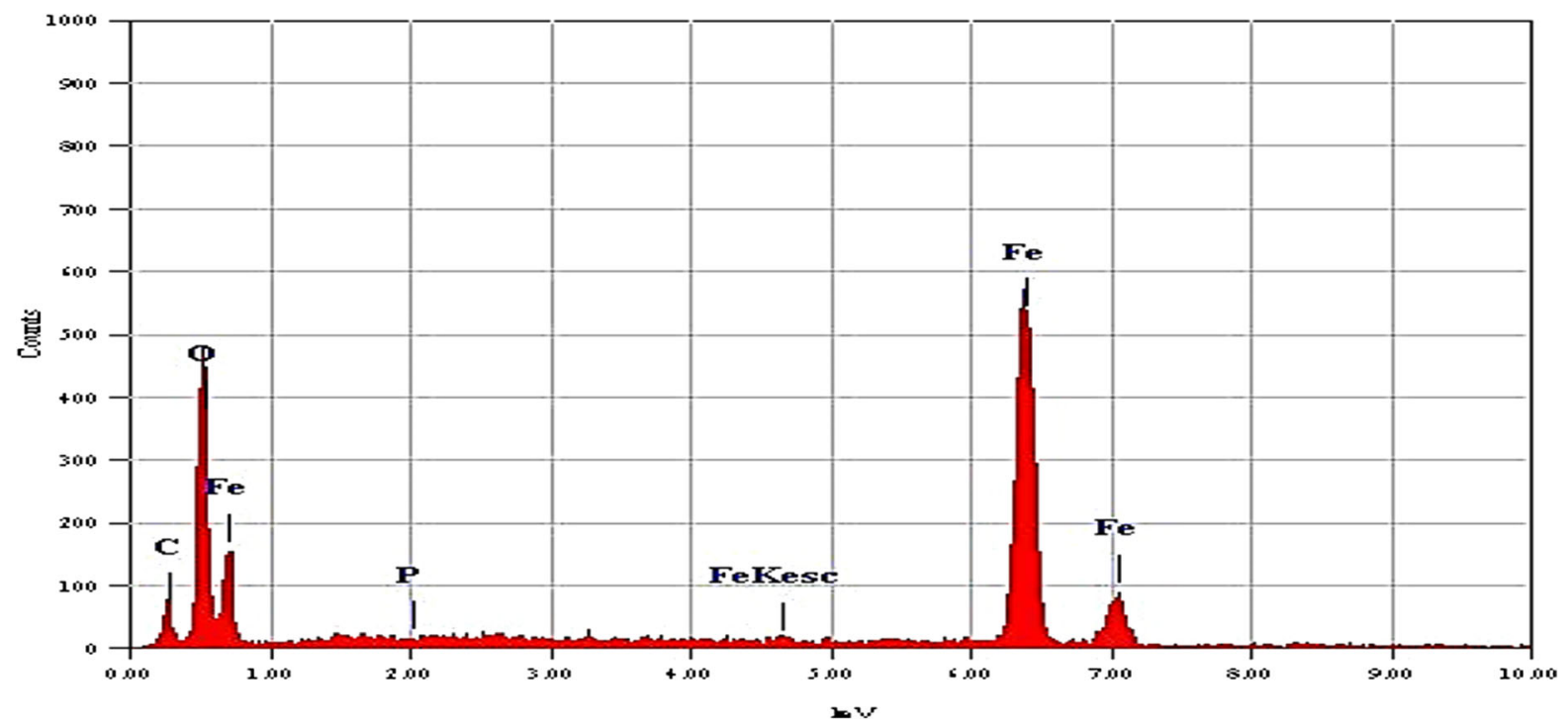

Fig. 4 EDX spectrum of MNP/HACP nanocomposite 


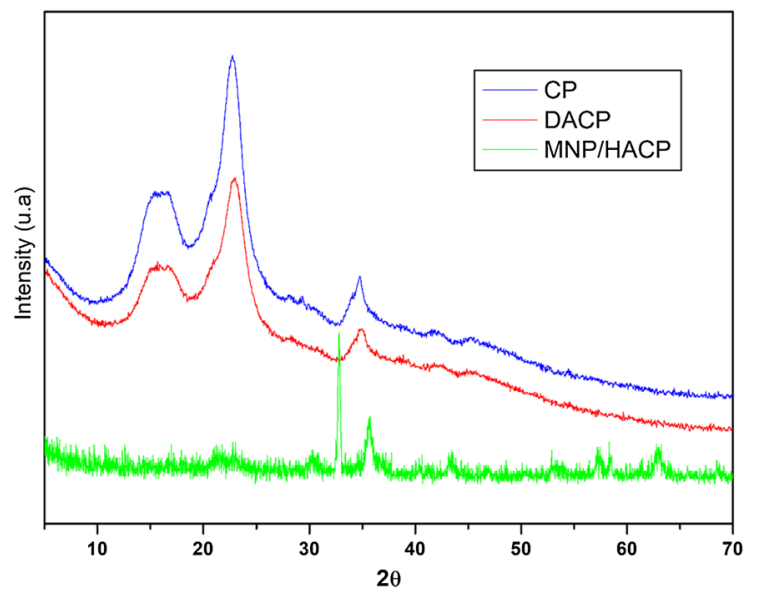

Fig. 5 XRD of CP, DACP, and MNP/HACP
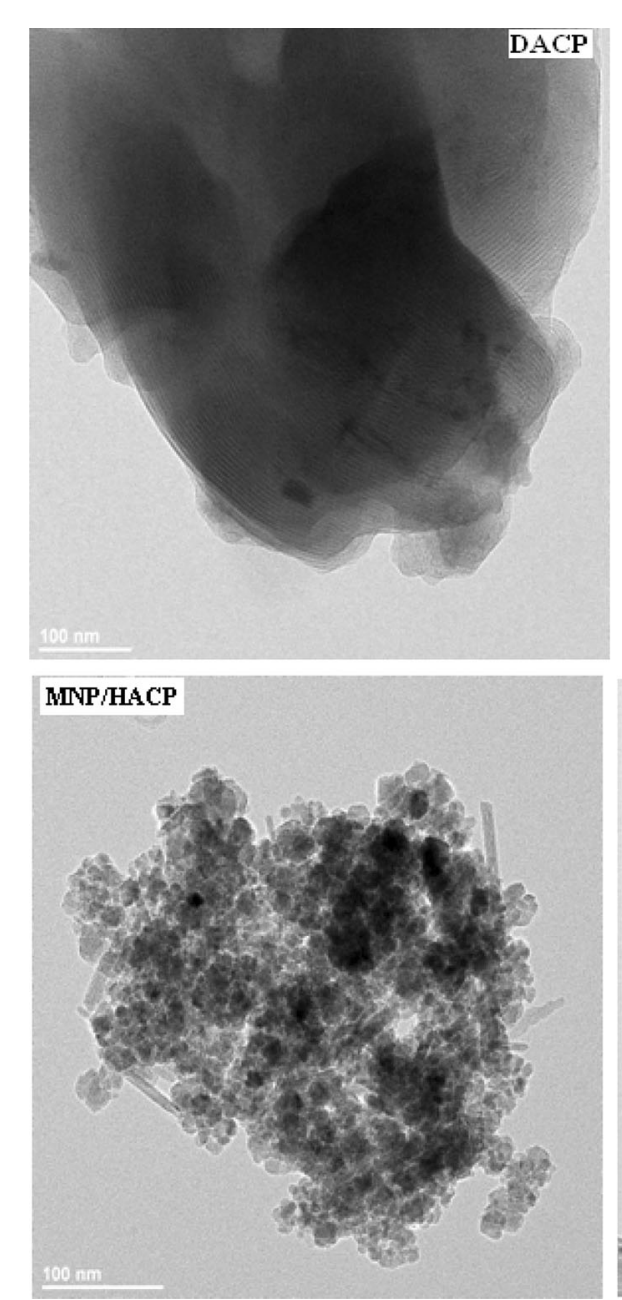

particles, independent or interacting particles, and isolated or aggregated particles. The magnetic properties of MNP/HACP were measured where the fieldcooled (FC) and zero-field-cooled (ZFC) magnetization curve under a field of 100 Oe were presented in Fig. 7a. A broad maximum appeared MNP/HACP with a fully separated FC and ZFC curves, merged after $300 \mathrm{~K}$. This finding reflects a superparamagnetic material with small particle size and consistency size distribution of MNP in the polymer which agrees with TEM analysis results (Nardi et al. 2013). The results support the formation of composite with a well separated and uniform distribution of MNP within the cellulosic moiety. The magnetization curve in Fig. $7 \mathrm{~b}$ indicates the presence of superparamagnetic
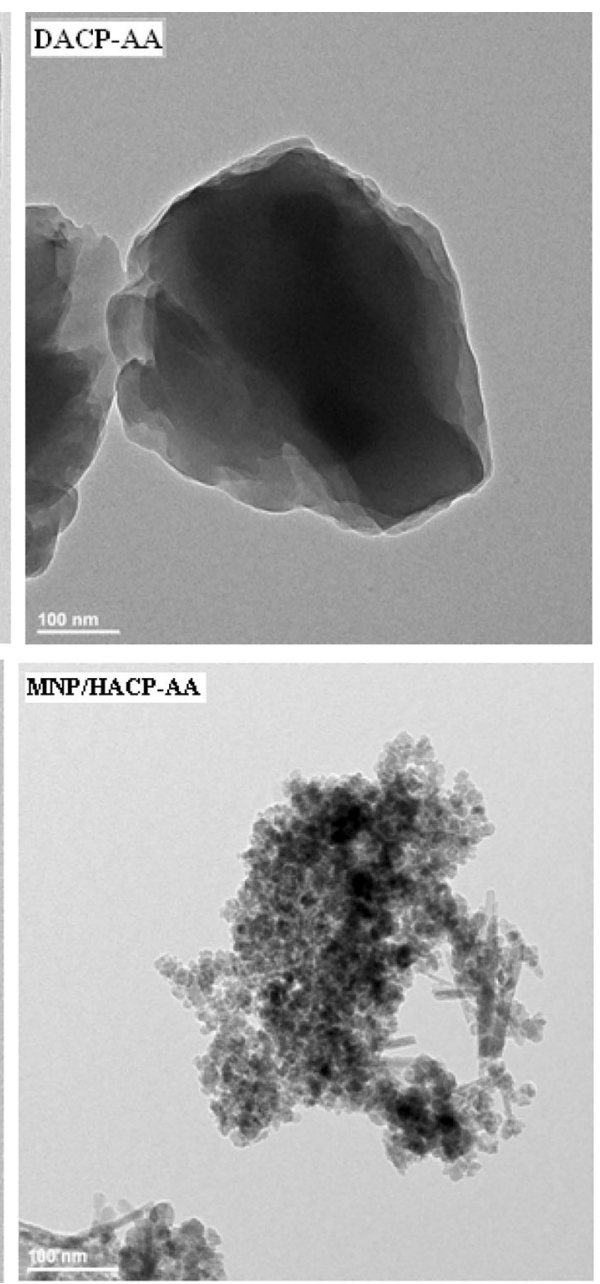

Fig. 6 TEM images for DACP, DACP-AA, MNP/DACP and MNP/DACP-AA as depicted 
material with a saturation magnetization (Ms) of $41 \mathrm{emu} / \mathrm{g}$, less than reported value of magnetite $88 \mathrm{emu} / \mathrm{g}$ (Jiang et al. 2004; Gomez-Lopera et al. 2001). The composites materials of superparamagnetic properties at room temperature were known to have preference for drug delivery systems as they do not keep magnetization before and after external magnetic field exposure, which reduce the probability of particle aggregation due to magnetic dipole attraction. The decrease in magnetization with composition could be due dilution effect and the effect of small particles on the surface (Kayal and Ramanujan 2010a).

Thermal stability of the prepared composite

The TGA results in Fig. 8 revealed that the presence of MNP within the HACP provides enhanced thermal stability and retards surface combustion if compared to the DACP. This finding could be explained as due to the formation of surface expanded layer on HACP by MNP, which increases the melt viscosity, and decreases the mobility of the molecules (Fernandes et al. 2002). The content of MNP (wt\%) in the composite MNP/HACP was calculated from the residue after thermal treatment. The weight residue after thermal degradation could provide quantitative information about the content of the sample. The residue after the final degradation step in the TGA curve of DACP and MNPs/HACP was found to be 21.28 and $53.8 \%$, respectively. The content of MNP in MNP/HACP was calculated to be $23.8 \%$.

In vitro loading investigation of 4-ampyrone

The loading of 4-ampyrone onto the prepared materials was performed via impregnation in drug solution. The amount of 4-ampyrone loaded was traced using UV-absorption analysis within the wavelength range 200-350 nm as presented in (Fig. 9) and concentration was calculated from the absorption peak at 240-245 $\mathrm{nm}$. The concentration-absorption relation was investigated to verify the concentration range to validate Lambert-Beer's law. The in vitro drug loading and release profile of 4-AA with DACP and $\mathrm{MNP} / \mathrm{HACP}$ was represented against time. The loading profile shows the rapid adsorption of 4-AA in the presence of MNP in the case of MNP/HACP (abs.1.30) rather than DACP (abs 1.35) in the initial stages. It is clear that the absorption rate slowed down after $45 \mathrm{~min}$ in MNP/HACP and $65 \mathrm{~min}$ in DACP, indicating the robust incorporation of MNPs into 4-AA. In addition, the absorption at 180 min was 0.7 for MNP/HACP and 1.0 for DACP, indicating that the presence of MNPs accelerates the absorption of drug.

The loading profile indicates quick adsorption of 4-AA onto MNP/HACP and the maximum loading
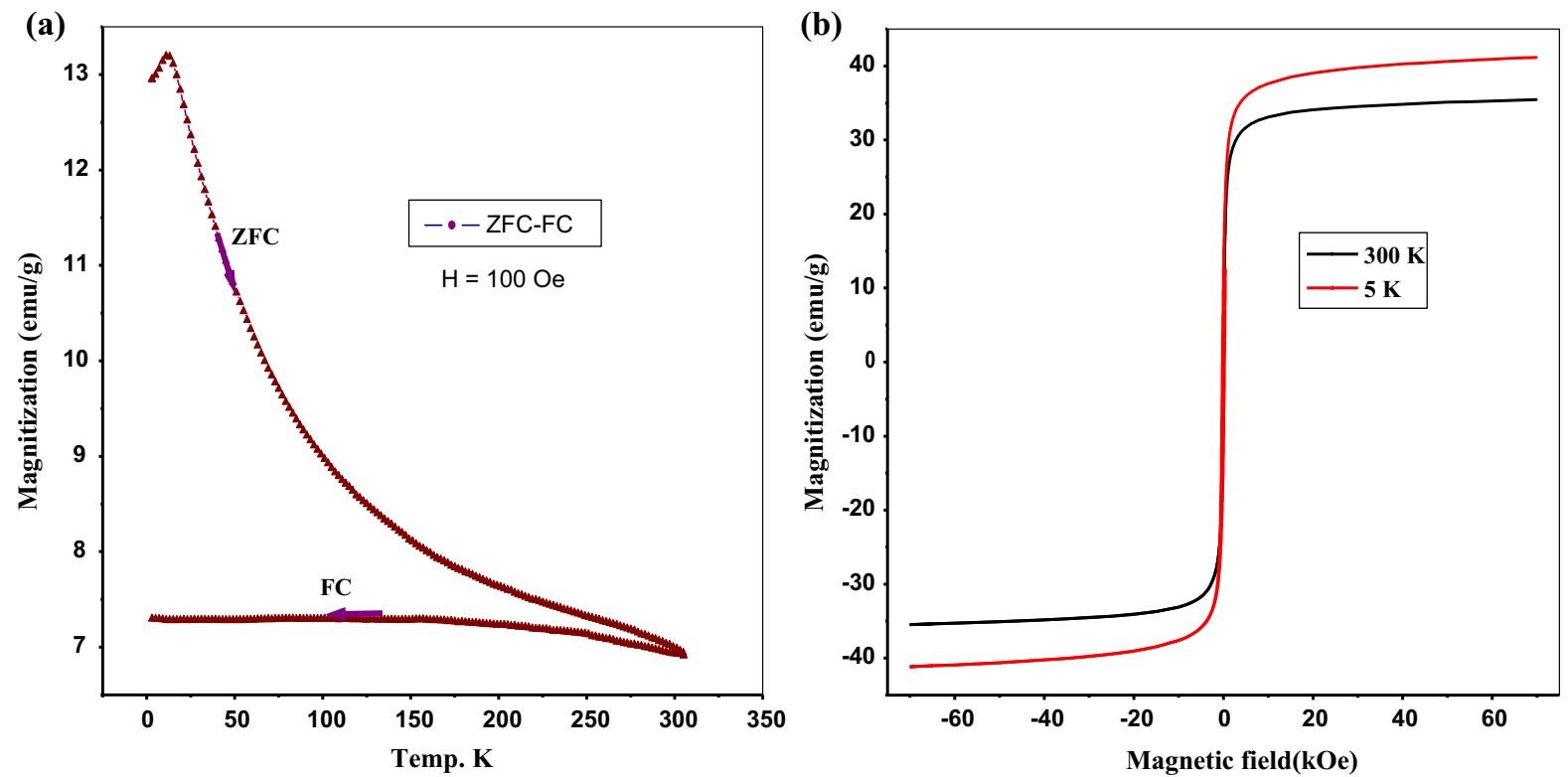

Fig. 7 Experimental FC-ZFC magnetization curves (a) and magnetization versus field curves measured at room temperature (b) 
TGA

mg

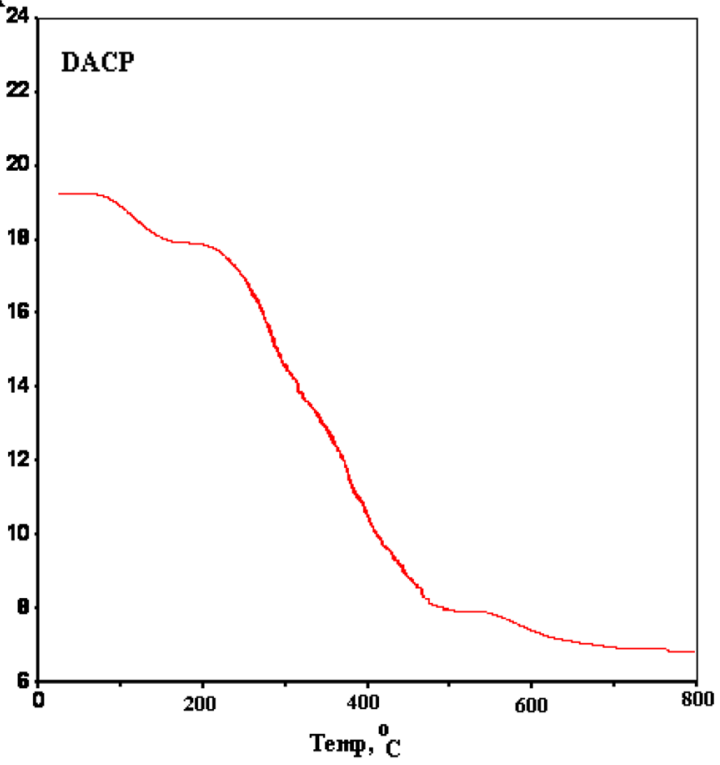

TGA

$\mathrm{mg}$

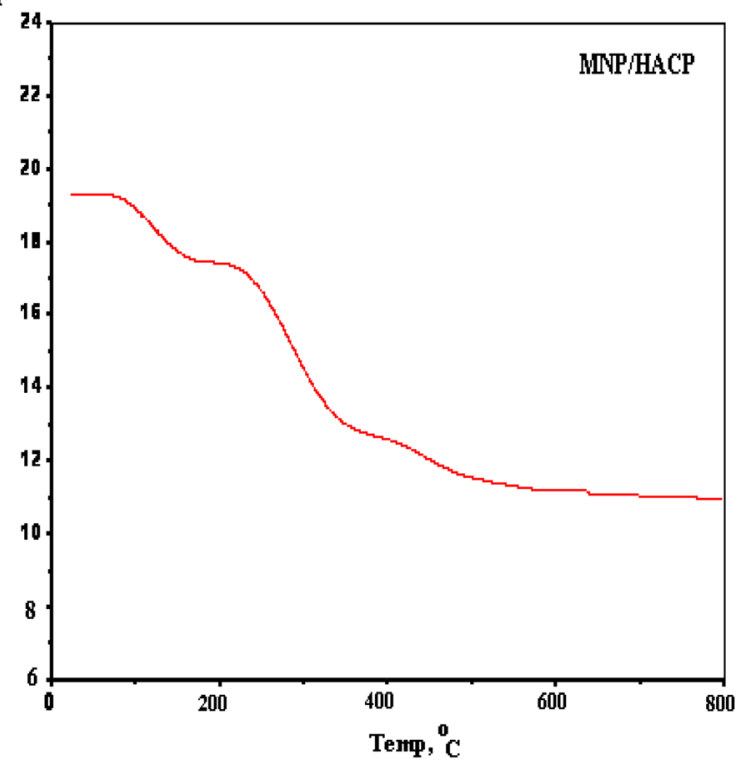

Fig. 8 TGA for DACP and MNP/HACP as depicted
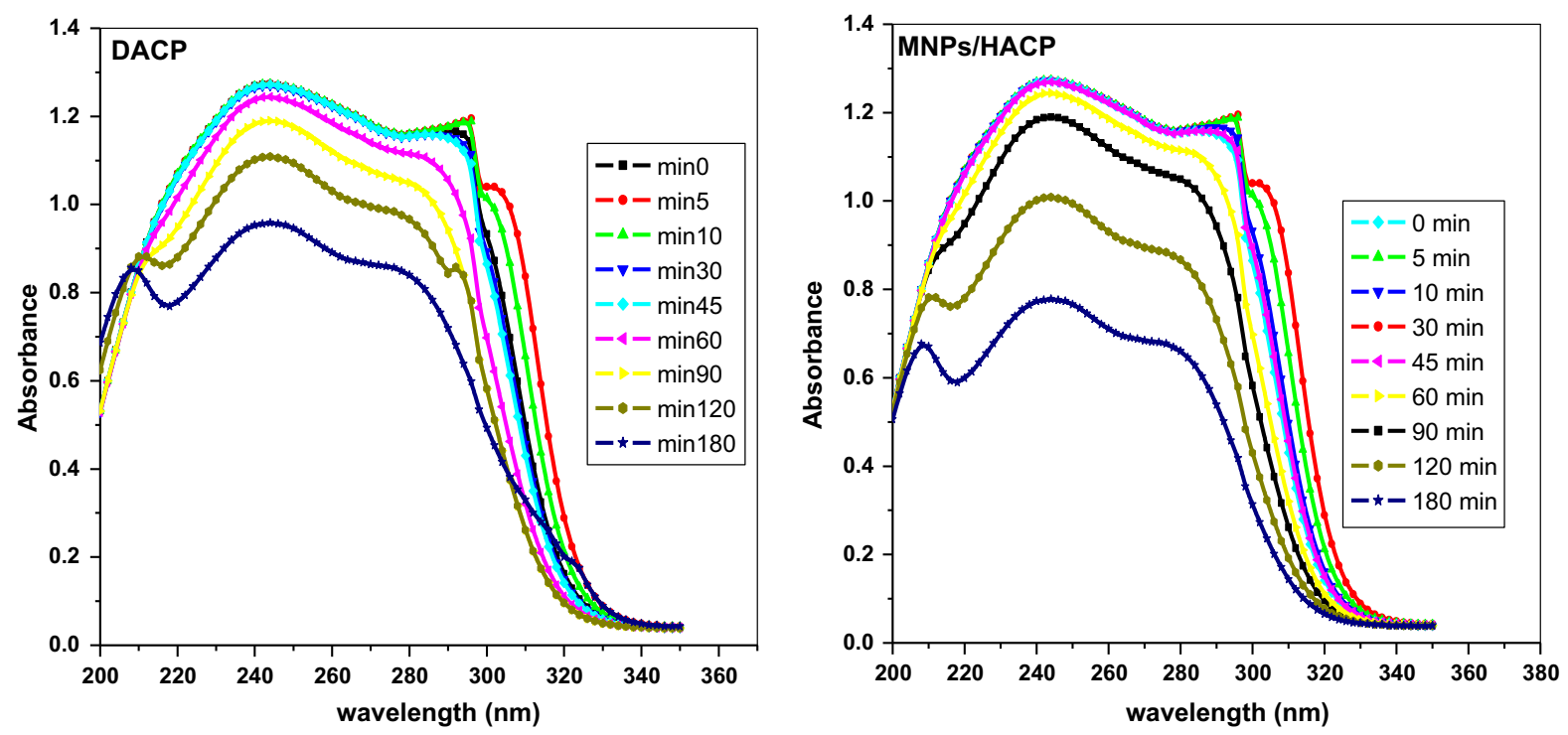

Fig. 9 Loading spectra of 4-ampyrone on DACP and MNP/HACP

was achieved in the first $60 \mathrm{~min}$, which subsequently slowed down due to surface saturation of the particles (Fig. 10).

For DACP, the loading behavior was slightly different compared to that of MNP/HACP where the greatest loading was deferred, and the amount of the drug loaded was lower.
The loading of 4-AA onto the MNP/HACP at various dosages could change the structure and surface morphology of the composite, and dispersion properties as well. It is worth mention that the presence of MNPs in the DACP contributes to enhancing the pore sizes because MNP breaks the intramolecular hydrogen bonds that connect the glucan chains. 
In vitro studies of release of ampyrone in phosphate buffer

The in vitro release assessment of 4-AA was achieved by placing pre-weighed, drug-loaded samples in phosphate buffer ( $\mathrm{pH}$ value of 7.5). At different time intervals, aliquots were removed and analyzed for concentrations of 4-AA, as described in the methods section. The dissolution medium was kept in a thermostatically controlled water bath at $37 \pm 0.5{ }^{\circ} \mathrm{C}$. The removed samples were replaced with equivalent volumes of fresh solution to keep the volume of released media constant. The higher density and the homogeneous, smaller pores in the DACP permitted a slower discharge rate. The in vitro release of 4-AA from the loaded DACP and MNP/HACP nanocrystals is shown in Figs. 8 and 9, respectively.

The release process of 4-AA from MNP/HACP occurred in two steps in the phosphate buffer at $\mathrm{pH} 7.4$ (Fig. 11). In the first step, there was a continuous release of $75 \%$ of the 4-ampyrone within $250 \mathrm{~min}$, and in the second step, a slow sustained released of 4-AA for 3000 min until nearly $100 \%$ of the drug was released. The rate of 4-AA released in phosphate buffer alone at $\mathrm{pH} 7.4$ was continuous, where the cumulative percentage of 4-AA released at $\mathrm{pH} 7.4$ was around $100 \%$ within $3000 \mathrm{~min}$. The release profile of

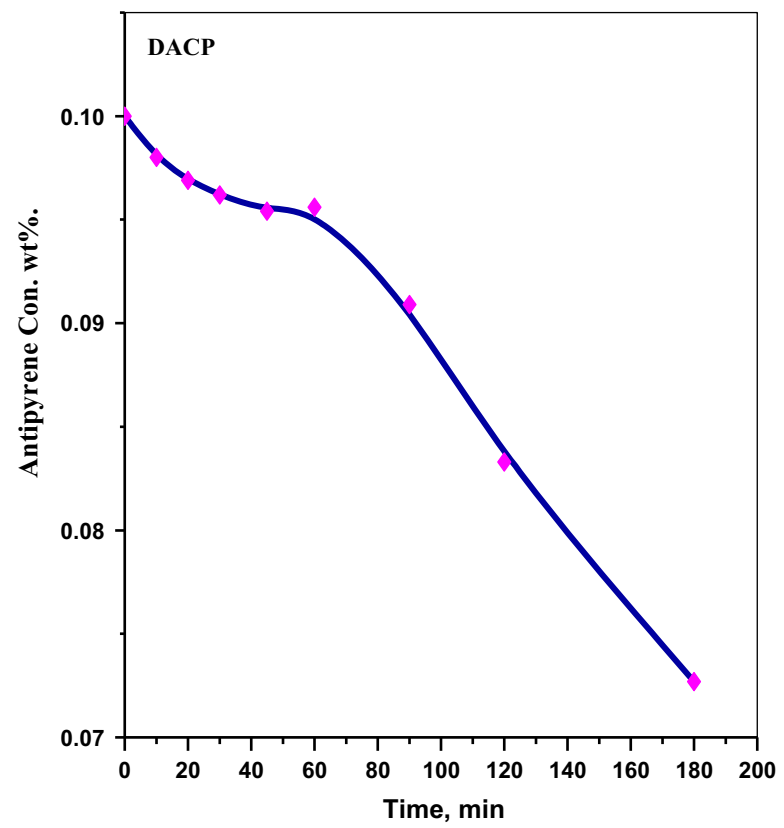

4-AA from DACP was found to be different from the release profile of 4-AA from MNP/HACP (Fig. 12).

The release of 4-AA from DACP in phosphate buffer at $\mathrm{pH} 7.4$ also occurred in two steps, where $60 \%$ of the loaded drug was released in a continuous manner within $195 \mathrm{~min}$ in the first step. In the second step, an additional 10\% was released within 3000 min. These results indicate that the bonding behavior in the 4-AA-MNP/HACP system was different to that of 4-AA-HACP under the same conditions. Moreover, MNP/HACP showed a nearly complete release compared to DACP. These observations highlight the role of MNPs within the composite. Drug delivery within the structures of the nanoparticle affects the release pattern because there is a higher amount of drug close to the surface or adsorbed onto the surface, and the initial burst effect is increased. In contrast, when the drug is predominantly captured inside the nanoparticle, as opposed to adsorbed onto the surface, the initial rapid release rate is reduced. Eruption release is a significant issue that should be considered in drug delivery at the nanoscale because of the high value of the surface to volume ratio. Furthermore, the release profile highly depends on the method of drug loading because the particle production method influences drug delivery (Francesca et al., 2006). The release profiles here show that the release rate was relatively

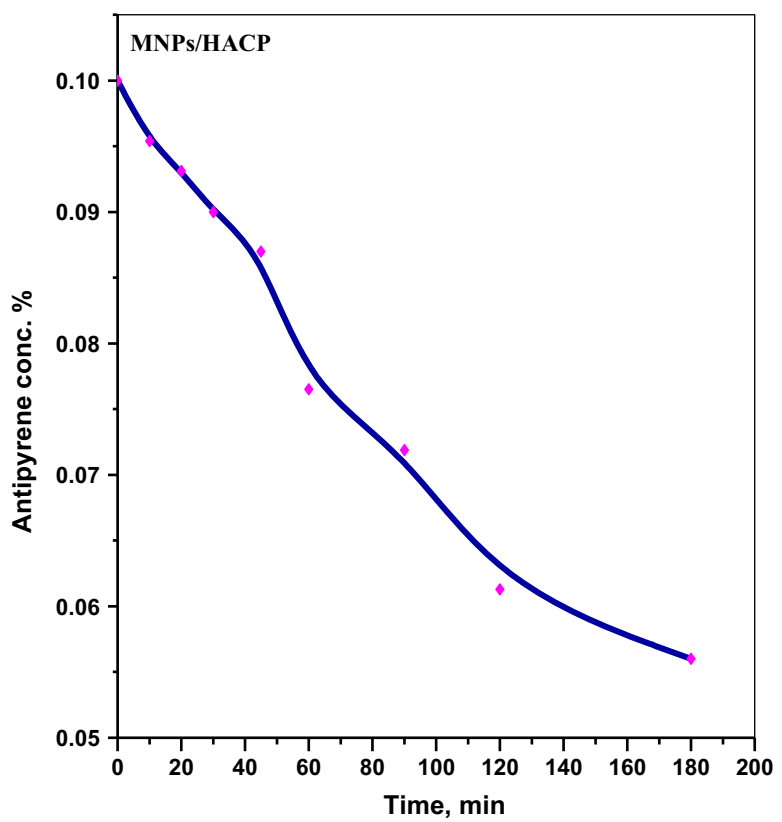

Fig. 10 Loading profile of 4-ampyrone on DACP and MNP/HACP 

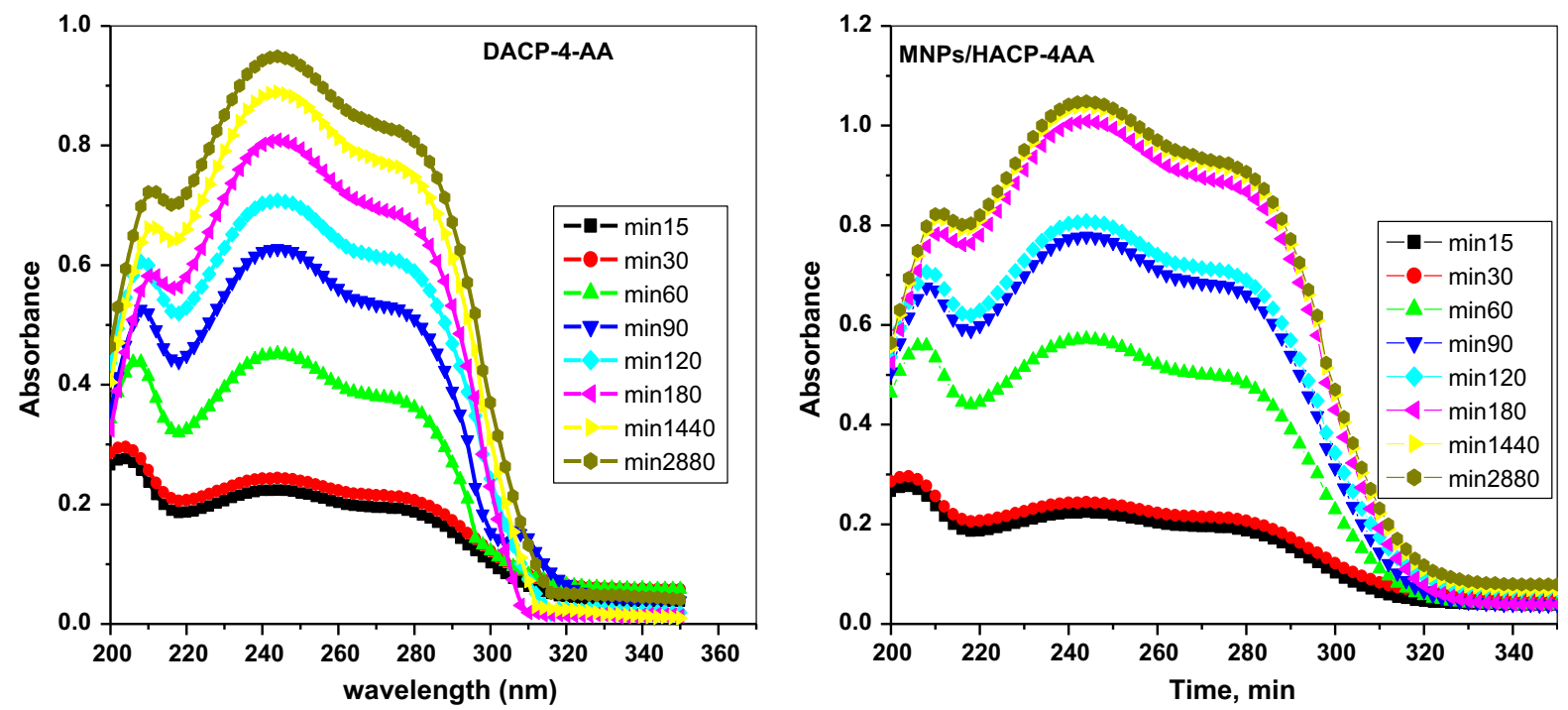

Fig. 11 Release spectra of 4-ampyrone from DACP and MNPs/HACP
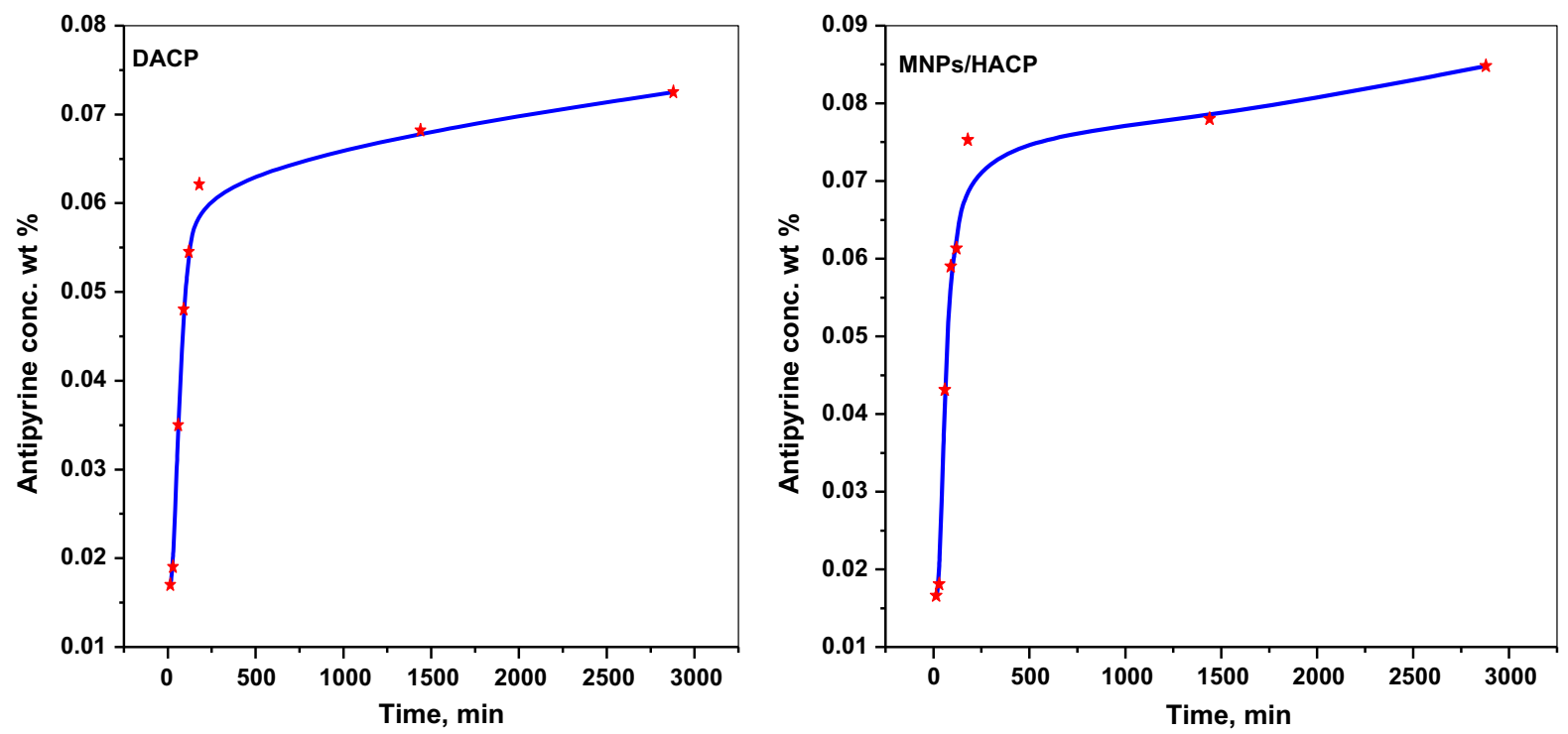

Fig. 12 Release profile of 4-ampyrone from DACP and MNP/HACP

slow when the time was prolonged (Fig. 12). It is clear that the drug release occurred quickly within the first $180 \mathrm{~min}$. This observation may be attributed to the excess of 4-AA molecules released from the matrix of the magnetic nanoparticle into the buffer solution, leading to the fast drug delivery (Longzhang et al. 2009). On the other hand, the subsequent slow release may be attributed to the inter-molecular hydrogen bonding of 4-AA with MNP/HACP, which delays the release of the drug. These results agree with previous studies, such as Kayal and Ramanujan (2010a, b). The results here show that MNP/HACP nanocomposites could be regarded as potential carrier systems for magnetic drugs, with applications for drug delivery.

\section{Conclusion}

In this study, a novel biocompatible nanocomposite $\mathrm{MNP} / \mathrm{HACP}$ was prepared and studied as a drug 
loading system for 4-AA drug and compared with DACP. The prepared materials were analysed using FTIR, SEM-EDX, XRD, TEM, VSM and TGA. The TEM and VSM analysis for prepared nanocomposite showed superparamagnetic material with small particle size and consistency size distribution of MNP in the polymer, by forming Schiff's base linkage and hydrogen bonds, respectively. Furthermore, the magnetic and morphological properties of the produced composite suggest their potential application in a controlled drug release system. DACP and MNP/ HACP nanocomposites showed excellent pH-regulated drug release behaviours. The in vitro release profile suggested that MNP/HACP could be regarded as potential forms of drug delivery carriers.

Acknowledgments The authors extend their appreciation to the Deanship of Scientific Research at King Khalid University for funding this work through research groups program under Grant Number R.G.P. 1/19/40. Thomas Heinze acknowledged financially supported by the DFG-funded Collaborative Research Centre PolyTarget (SFB 1278, Project A02).

\section{References}

Aguilera G, Berry C, West R, Gonzalez-Monterrubio E, Angulo-Molina A, Arias-Carri'on O, Angel M'endez-Rojas M (2019) Carboxymethyl cellulose coated magnetic nanoparticle transport across a human lung microvascular endothelial cell model of the blood-brain barrier. Nanoscale Adv 1:671-685

Alam MS, Choi JH, Lee D (2012) Synthesis of novel Schiff base analogues of 4-amino-1, 5-dimethyl-2-phenylpyrazol-3one and their evaluation for antioxidant and anti-inflammatory activity. Bioorg Med Chem 20(13):4103-4108

Allia P, Barrera G, Tiberto P, Nardi T, Leterrier Y, Sangermano $\mathrm{M}$ (2014) $\mathrm{Fe}_{3} \mathrm{O}_{4}$ nanoparticle and nanocomposites with potential application in biomedicine and in communication technologies: nanoparticle aggregation, interaction, and effective magnetic anisotropy. J Appl Phys 116(11):113903

Dias F, Duarte C (2013) Cellulose and its derivatives use in the pharmaceutical compounding practice. In: Van De Ven TGM (ed) Cellulose-medical pharmaceutical and electronic applications. In Tech Open, Croatia, pp 141-162

Edgar KJ (2004) Cellulose esters, organic. In: Korschwitz J (ed) Encyclopedia of polymer science and technology, $3^{\text {rd }}$ edn. pp 131-133. Wiley, New York

Edgar KJ (2007) Cellulose esters in drug delivery. Cellulose $14: 49-64$

El-kott A, Syef AF, Alshehri MA, Al Dosage S, Keshk SMAS (2019) Suppression efficacy of lignosulfonate/mercerized cotton composite against cancer cell's activities. Adv Compos Lett 28:1-9
Fernandes VJ Jr, Araujo AS, Fonseca VM, Fernandes NS, Silva DR (2002) Thermogarvimetric evaluation of polyester/sisal flame retarded composite. Thermochem Acta 392-393:71-77

Francesca U, Giuseppe R, Agnese M, Fabiana Q, Maria R (2006) Cyclodextrins in the production of large porous particles: development of dry powders for the sustained release of insulin to the lungs. Eur J Pharm Sci 28:423-432

Fricain JC, Granja PL, Barbosa MA, de Jeso B, Barthe N, Baquey C (2001) Cellulose phosphates as biomaterials. In vivo biocompatibility studies. Biomaterials 23:971-980

Frisch MJ, Trucks GW, Schlegel HB et al. (2009) Gaussian-09, Revision A.1, 483 Gaussian, Inc., Wallingford, CT

Godwin A, Bolina K, Clochard M, Dinand E, Rankin S, Simic S, Brocchini S (2001) New strategies for polymer development in pharmaceutical science- a short review. J Pharm Pharmacol 53:1175-1184

Gomez-Lopera SA, Plaza RC, Delgado AV (2001) Synthesis and characterization of spherical magnetite/biodegradable polymer composite particles. J Colloid Interface Sci 240(1):40-47

Heinze T, Liebert TF, Pfeiffer KS, Hussain MA (2003) Unconventional cellulose esters: synthesis, characterization and structure-property relations. Cellulose 10:283-296

Irfan A, Chaudhry AR et al (2017) Exploring the charge transfer nature and electro-optical properties of anthracene-based sensitizers @ $\mathrm{TiO}_{2}$ cluster. J Taiwan Inst Chem Eng 80(Supplement C):239-246

Jiang W, Yang HC, Yang SY, Horng HE, Hung JC, Chen YC, Hong CY (2004) Preparation and properties of superparamagnetic nanoparticle with narrow size distribution and biocompatible. J Magn Magn Mater 283:210-215

Kayal S, Ramanujan RV (2010a) Doxorubicin loaded PVA coated iron oxide nanoparticle for targeted drug delivery. Mater Sci Eng C 30:484-490

Kayal S, Ramanujan RV (2010b) Doxorubicin loaded PVA coated iron oxide nanoparticle for targeted drug delivery. Mater Sci Eng C 30(3):484-490

Keshk SMAS, Salah M (2014) Bacterial cellulose and its phosphoric dichloride for efficient removal of metal ions. Amer J Polym Sci 4:10-16

Keshk SMA, Gouda M (2017) Natural biodegradable medical polymers: cellulose. In: Xiang Z (ed) Science and principles of biodegradable and bioresorbable medical polymersmaterials and properties, pp 279-294. Elsevier, ISBN: 978-0-08-100372-5

Keshk SMAS, Bondock S, El-Zahhar A, Abu Haija M (2019a) Synthesis and characterization of novel Schiff's bases derived from cellulose phosphate 2,3-dialdehyde. Cellulose 26:3703-3712

Keshk SMAS, Bondock S, Youssef AMS, El-Zahhar A (2019b) Novel synthesis of flame-retardant magnetic nanoparticle/ hydroxyl acid cellulose-6-phosphate composite. Mater Res Express 6(8):085310

Keshk SMAS, El-Zahhar A, Al-Sehemi AG, Irfan A, Bondock S (2019c) Synthesis and physicochemical characterization of a magnetic nanoparticle/dialdehyde cellulose composite as a flame retardant. Mater Res Express 6(2):025312 
Kim S, Kim JH, Jeon O, Kwon IC, Park K (2008) Engineered polymers for advanced drug delivery. Eur J Pharm Biopharm 71:420-430

Koksharov YA (2009) Magnetism of nanoparticle: effects of size, shape, and interactions. In: Gubin SP (ed) Magnetic nanoparticle. Wiley-VCH Verlag $\mathrm{GmbH} \& \mathrm{Co}$. KGaA, Weinheim, pp 197-254

Leone G, Torricelli P, Giardino R, Barbucci R (2008) New phosphorylated derivatives of carboxymethylcellulose with osteogenic activity. Polym Adv Technol 19:824-830

Liechty WB, Kryscio DR, Slaughter BV, Peppas NA (2010) Polymers for drug delivery systems. Annu Rev Chem Biomol Eng 1:149-173

Longzhang Z, Jingwei M, Nengqin J, Yu Z, Hebai S (2009) Chitosan-coated magnetic nanoparticle as carriers of 5-fluorouracil: preparation, characterization and cytotoxicity studies. Colloids Surf B Biointerfaces 68:1-6

Nardi T, Sangermano M, Leterrier Y, Allia P, Tiberto P, Månson JAE (2013) UV-cured transparent magnetic polymer nanocomposites. Polymer 54:4472-4479

Patitsa M, Karathanou K, Kanaki Z, Tzioga L, Pippa N, Demetzos C, Verganelakis D, Cournia Z, Klinakis A (2017) Magnetic nanoparticle coated with polyarabic acid demonstrate enhanced drug delivery and imaging properties for cancer theranostic applications. Sci Rep 7:775-782

Pham XN, Nguyen TP, Pham TN, Nga TT (2010) Synthesis and characterization of chitosan coated magnetite nanoparticle and their application in curcumin drug delivery. Adv Nat Sci Nanosci Nanotechnol 7:045010

Qu J-B, Shao H-H, Jing G-L, Huang F (2013) PEG-chitosan coated iron oxide nanoparticle with high saturated magnetization as carriers of 10-hydroxycamptothecin: preparation, characterization and cytotoxicity studies. Colloids Surf B 102:37-44

Radi S, Toubi Y, Hamdani I, Hakkou A, Souna F, Himri I, Bouakka M (2012) Synthesis, antibacterial and antifungal activities of some new bipyrazolic tripodal derivatives. Res J Chem Sci 2(4):40-44

Shokri J, Adibki K (2013) Application of cellulose and cellulose derivatives in pharmaceutical industries. In: Van De Ven TGM (ed) Cellulose-medical, pharmaceutical and electronic applications. In Tech Open, Croatia, pp 47-66

Urquiza E, Cardona F, Duarte C, Cole B, Wu B, Méndez-Rojas M, Cherr G (2017) Facilitation of trace metal uptake in cells by inulin coating of metallic nanoparticle. R Soc Open Sci 4:170480

Volkert B, Wolf B, Fischer S, Li N, Lou C (2009) Application of modified bead cellulose as a carrier of active ingredients. Macromol Symp 280:130-135

Yao Y, Miao S, Yu S, Ping Ma L, Sun H, Wang S (2012) Fabrication of $\mathrm{Fe}_{3} \mathrm{O}_{4} / \mathrm{SiO}_{2}$ core/shell nanoparticle attached to graphene oxide and its use as an adsorbent. J Colloid Interface Sci 379:20-26

Zhang WF, Zhang YH, Jiang Q, Zhao WJ, Yu AJ, Chang H, Lu XM, Xie FW, Ye BX, Zhang SS (2016) Tetraazacalix [2] arence [2] triazine coated $\mathrm{Fe}_{3} \mathrm{O}_{4} / \mathrm{SiO}_{2}$ magnetic nanoparticle for simultaneous dispersive solid phase extraction and determination of trace multitarget analytes. Anal Chem 88:10523-10532

Publisher's Note Springer Nature remains neutral with regard to jurisdictional claims in published maps and institutional affiliations. 